\title{
Níveis do Subproduto Concentrado da Produção de Lisina em Dietas com Alto Concentrado para Tourinhos Santa Gertrudes em Terminação ${ }^{1}$
}

\author{
Wignez Henrique ${ }^{2}$, Paulo Roberto Leme ${ }^{3}$, Dante Pazzanese Duarte Lanna ${ }^{4}$, Guilherme \\ Fernando Alleoni ${ }^{5}$, Alexandre Amstalden Moraes Sampaio ${ }^{6}$
}

\begin{abstract}
RESUMO - O experimento foi realizado objetivando-se caracterizar o subproduto concentrado da produção de lisina (SPL) e avaliar o desempenho e as características de carcaça de tourinhos Santa Gertrudes confinados recebendo níveis crescentes desse subproduto na dieta. O SPL resulta do processo de produção de lisina e é parcialmente seco. Apresentou aproximadamente 38\% de matéria seca e 85\% de proteína bruta na matéria seca, sendo que 79\% desse nitrogênio encontrava-se na forma não-protéica. Não foram observados metais pesados em níveis tóxicos. Vinte e sete animais, com dez meses de idade e peso inicial de $242 \mathrm{~kg}$, receberam silagem de milho, $80 \%$ de concentrado e $0 ; 4,5$ ou 9,0\% de SPL na matéria seca da dieta. O período experimental foi de 115 dias, após 56 dias de adaptação. A inclusão do SPL na dieta determinou efeito quadrático sobre o ganho de peso, o consumo diário de matéria seca, o peso final e o peso de carcaça; efeito linear decrescente sobre a eficiência alimentar e o rendimento de carcaça; e aumento da espessura de gordura de cobertura e do peso do fígado. Não foram observadas diferenças entre tratamentos para a área de olho de lombo. As diferenças no desempenho não foram associadas ao menor consumo de alimentos ou ao teor de enxofre das dietas. O nível de 3,7\% de SPL na matéria seca da dieta foi considerado o máximo recomendado para tourinhos em terminação recebendo dietas com alto teor de energia, quando o ganho diário de peso esperado seria de $1,23 \mathrm{~kg} / \mathrm{animal}$.
\end{abstract}

Palavras-chave: aminoácidos, bovinos de corte, confinamento, minerais, resíduo

\section{Effects of Feeding Different Levels of a By-product of Lysine Production on Finishing Santa Gertrudis Young Bulls Fed High Energy Diets}

\begin{abstract}
The objective of this trial was to characterize the byproduct of lysine production (BLP) and to evaluate performance and carcass traits of confined Santa Gertrudis young bulls receiving increasing dietary levels of BLP. The chemical composition of BLP was the following (dry matter basis): 38\% dry matter and 85\% crude protein with 79\% of this total coming from nonprotein nitrogen; no toxic levels of heavy metals were detected. Twenty-seven young bulls averaging ten months of age and initial body weight of $242 \mathrm{~kg}$ were used in this trial. Animals received corn silage plus 80\% of concentrate and one of the following levels of BLP: 0, 4.5 or 9.0\% on dry matter basis. The experimental period lasted 115 days with 56 days for diet adaptation. Average daily weight gain, dry matter intake, final weight, and carcass weight all responded quadraticaly when the dietary levels of BLP increased from 0 to $9.0 \%$. Feed efficiency and carcass dressing decreased linearly while fat thickness and liver weight increased linearly with incremental levels of BLP in the diet. No significant differences for Longissimus muscle area were observed across treatments. Lower feed intake or dietary sulfur levels did not explain the observed differences in the performance. The maximum recommended dietary level of BLP for finishing young bulls fed high energy diets was $3.7 \%$ for expected daily weight gain of $1.23 \mathrm{~kg}$ per animal.
\end{abstract}

Key Words: aminoacids, beef cattle, feedlot, minerals, residue

\section{Introdução}

A lisina, sólido de cor clara utilizado nas indústrias de rações animais, é resultante da fermentação do xarope de cana-de-açúcar com bactérias do gênero Brevibacterium adicionado de algumas substâncias. Ao final desse processo de produção, além da lisina, obtém-se um subproduto aquoso, de concentração parcial, denominado subproduto concentrado da produção de lisina (SPL). No Brasil, sua produção se iniciou em meados do ano de 1996 e tem aumentado largamente no decorrer dos anos. Outros países, como Rússia, Estados Unidos, Alemanha eHungria, também produzem lisina e SPL, que recebe diferentes denominações: condensed molasses solubles (CMS) e liquido aminobakterian, entre outras (Bokori et al., 1992; Zakharyan et al., 1986).

\footnotetext{
1 Projeto financiado pela Ajinomto Biolatina Ind. e Com. Ltda.

2 Pesq. Científico, Instituto Zootecnia, São José do Rio Preto, SP (wignez@terra.com.br).

3 Professor, Depto. Zootecnia/FZEA/USP, Pirassununga, SP, Bolsista CNPq (prleme@usp.br).

4 Professor, Depto. Zootecnia/ESALQ/USP, Piracicaba, SP, Bolsista CNPq (dplanna@esalq.usp.br).

5 Pesquisador Científico, Instituto de Zootecnia, Nova Odessa, SP (alleoni@iz.sp.gov.br).

6 Professor, Depto. Zootecnia/FCAV/UNESP, Jaboticabal, SP, Bolsista CNPq (sampaio@fcav.unesp.br).
} 
Segundo Bokori et al. (1992), o CMS (condensed molasses solubles) é um líquido viscoso de cor marrom, com leve odor de melaço e $\mathrm{pH}$ variando de 4,5 a 4,7. Em análise do CMS, esses autores registraram valores de $79 \%$ de proteína bruta na matéria seca, sendo $10 \%$ de proteína verdadeira e $93 \%$ de digestibilidade em pepsina e, na composição mineral, 3,2\% de sódio, 48 ppm de zinco e 18 ppm de manganês. Os níveis de cádmio, mercúrio, arsênio e chumbo atenderam os limites máximos permitidos. Os teores de lisina e metionina foram, respectivamente, de 1,04 e 0,199\% da matéria seca. A concentração de riboflavina foi cinco vezes a encontrada em levedura de cerveja, mas a de vitaminas lipossolúveis foi baixa.

Zakharyan et al. (1986) estimaram, no liquido aminobakterian, 38 a $40 \%$ de matéria seca; $50 \%$ de proteína bruta; de 6 a 6,5\% de matéria mineral; 3,2\% de extrato etéreo; e $0,8 \%$ de fibra bruta na matéria seca. Hannon \& Trenkle (1990) obtiveram no CMS (condensed molasses solubles) 45,6\% de matéria seca; 5,87\% de nitrogênio (36,7\% de proteína bruta); 7,36\% de minerais; 5,75\% de enxofre; e pH de 5,21. No entanto, Ulbrich et al. (1993), na Alemanha, calcularam $57 \%$ de proteína bruta, das quais $14 \%$ estão na forma de proteína verdadeira e o restante como aminoácidos livres e amônia. Oliveira et al. (2000), ao caracterizarem o SPL no Brasil, registraram 38,2\% de matéria seca; 75,6\% de proteína bruta; 10,8\% de nitrogênio não protéico; 12,1\% de nitrogênio total; e 9,6\% de matéria mineral e, ao determinarem a composição mineral e de aminoácidos, não detectaram a presença de selênio, cádmio e arsênio.

Ulbrich et al. (1993) observaram redução de 374 para 241 g no ganho de peso diário de cabritos em terminação com a inclusão de 5\% de resíduo da hidrólise do farelo de soja para produção de lisina. Entretanto, adicionando CMS ao volumoso, Fekete et al. (1992) obtiveram aumento de até $34 \%$ no ganho de peso de novilhas com o fornecimento de 400 e $600 \mathrm{~mL}$ por dia. O maior ganho de peso foi conseqüência do aumento na ingestão de matéria seca, na glicose sangüínea e na concentração de uréia ruminal; o fígado foi mantido em bom estado. Os autores recomendaram dose de 1,0 a 1,5 g de CMS por kg de peso vivo do animal para aumento do ganho de peso.

A qualidade da dieta parece ser fator preponderante na resposta da utilização e da quantidade utilizada de SPL para animais em engorda. Oliveira et al. (2000) avaliaram os níveis de 300 e $600 \mathrm{~mL}$ por dia para bovinos em terminação recebendo dietas com $65 \%$ de volumoso e concluíram que o nível mais baixo possibilitou melhoria no desempenho animal, mas o nível de $600 \mathrm{~mL}$, apesar de não ter afetado o consumo de matéria seca, reduziu o ganho de peso e, conseqüentemente, piorou a conversão alimentar. Os autores consideraram a silagem utilizada de baixa qualidade e mesmo a adição de caldo de cana concentrado como palatabilizante não alterou os parâmetros avaliados. Calixto (2001), embora tenha avaliado o efeito do uso de ionóforo, concluiu que a associação do bagaço de cana-de-açúcar, hidrolisado e cru, com o SPL não foi adequada em razão da degradabilidade das frações obtidas.

Porém, em dietas com altos teores de concentrado (77\%), Endres \& Trenkle (1990) constataram redução no consumo de alimentos e no ganho de peso de novilhos confinados apenas com 10\% de CMS na matéria seca da dieta. Abaixo desse nível, o desempenho não foi alterado. O rendimento de carcaça e a área de olho de lombo não foram afetados pelos níveis de CMS, mas a espessura de gordura de cobertura e a gordura renal-pélvica-inguinal foram menores nos animais que receberam o nível mais elevado de CMS e todos esses efeitos foram atribuídos ao menor consumo de alimentos.

Hannon \& Trenkle (1990) propuseram que o teor de enxofre do CMS seria a causa da redução linear da quantidade de alimento ingerido e do ganho de peso, uma vez queforam utilizados níveis de 0; 2,5; e 5,0\% desse subproduto na matéria seca da dieta, que possía $40 \%$ de volumoso em sua concentração. Esses autores relataram ter encontrado recomenações de níveis máximos de $0,3 \%$ de enxofre na dieta para não haver redução do consumo. Esse nível é inferior ao de 0,4\% sugerido pelo NRC (1996), mas as concentrações de enxofre nas dietas avaliadas foram de 0,46 e $0,64 \%$ para os tratamentos com 2,5 e 5,0\% de CMS, respectivamente. Os autores concluíram que apenas parte da uréia pode ser substituída pelo CMS e que, em dietas com menor necessidade de nitrogênio suplementar, contendo silagem de milho e/ou altos teores de concentrado, o CMS pode ser uma fonte de nitrogênio não-protéico mais efetiva.

Endres \& Trenkle (1991) afirmaram que o enxofre é a principal causa do efeito depressor no consumo de alimentos, apesar de sua interação com outros componentes do CMS também afetar o consumo de alimentos quando em altas quantidades na dieta. 
O objetivo neste trabalho foi caracterizar laboratorialmente o subproduto concentrado da produção de lisina e avaliar o efeito de sua inclusão em dietas com elevada proporção de concentrado sobre o desempenho e as características da carcaça de tourinhos Santa Gertrudes em confinamento.

\section{Material e Métodos}

Inicialmente, o subproduto concentrado da produção de lisina (SPL) foi caracterizado por meio de análises laboratoriais. A composição em princípios nutritivos e antinutritivos foi determinada segundo recomendações da AOAC (1995); a concentração em aminoácidos, por cromatografia líquida; e os minerais e metais pesados, após digestão nitro-perclórica e leitura em espectofotômetro.

Utilizaram-se 27 animais machos Santa Gertrudes, não-castrados, com idade média de 10 meses e peso inicial de $242 \mathrm{~kg}$, provenientes do rebanho do Instituto de Zootecnia de São José do Rio Preto, mantidos confinados em baias coletivas da desmama até o início do experimento.

Durante o experimento, os animais foram mantidos confinados em baias individuais parcialmente concretadas e com cocho coberto, com livre acesso à água, sendo distribuídos em delineamento de blocos ao acaso, de acordo com o peso inicial, com nove repetições. Foram testados os seguintes tratamentos: controle (sem a adição do SPL); 4,5\% da matéria seca da dieta na forma de SPL, em substituição à uréia e ao sulfato de amônio e parte do farelo de soja; 9,0\% de SPL na matéria seca da dieta, em substituição à uréia e ao sulfato de amônio e parte do farelo de soja.

$\mathrm{Na}$ formulação das dietas, foram consideradas as exigências de energia e proteína, sendo ajustadas pelo modelo Cornell Net Carbohydrate and Protein System - CNCPS (Sniffen et al., 1992) para atenderem às exigências de proteína degradável no rúmen, proteína metabolizável, aminoácidos e peptídeos das bactérias do rúmen para a categoria animal utilizada. O volumoso utilizado durante o confinamento foi silagem de milho, composta por $40 \%$ da matéria seca na forma de grãos, conforme porcentagem calculada em amostras retiradas da cultura no campo. A composição das dietas experimentais encontra-se na Tabela 1.

O tratamento com $4,5 \%$ de SPL foi definido segundo o teor máximo estimado em simulações com o CNCPS, com base nos dados de composição obtidos na caracterização do SPL. O tratamento com 9,0\% de SPL foi exatamente o dobro do máximo sugerido pelo modelo, buscando-se traçar a curva de regressão da inclusão do SPL na dieta de animais confinados.

$\mathrm{Na}$ análise químico-bromatológica de alguns dos ingredientes utilizados na composição das dietas é apresentada na Tabela 2 . As concentrações de matéria seca, proteína bruta, nitrogênio amoniacal, matéria mineral, cálcio e fósforo foram realizadas utilizando-se metodologia da AOAC (1995) e as de fibra em detergente neutro, de acordo com técnica descrita por Van Soest et al. (1991).

Os animais receberam diariamente duas refeições, na forma de ração completa, permitindo-se em torno de $10 \%$ de sobras. A proporção de volumoso foi corrigida diaria e individualmente, conforme a quantidade de alimento consumida no dia anterior, e a de

Tabela 1 - Composição das dietas experimentais (porcentagem da matéria seca)

Table 1 - Composition of experimental diets (percentage of dry matter)

\begin{tabular}{|c|c|c|c|}
\hline \multirow[t]{2}{*}{$\begin{array}{l}\text { Ingrediente } \\
\text { Ingredient }\end{array}$} & \multicolumn{3}{|c|}{$\begin{array}{l}\text { Tratamento - Porcentagem SPL } \\
\text { Treatment - BLP percentage }\end{array}$} \\
\hline & 0 & 4,5 & 9,0 \\
\hline $\begin{array}{l}\text { Silagem de milho } \\
\text { Corn silage }\end{array}$ & 20,00 & 20,00 & 20,00 \\
\hline $\begin{array}{l}\text { Milho em grão triturado } \\
\text { Ground corn grain }\end{array}$ & 26,30 & 25,40 & 27,10 \\
\hline $\begin{array}{l}\text { Polpa cítrica peletizada } \\
\text { Citrus pulp pellets }\end{array}$ & 40,00 & 40,00 & 40,00 \\
\hline $\begin{array}{l}\text { Farelo de soja } \\
\text { Soybean meal }\end{array}$ & 12,00 & 9,00 & 2,80 \\
\hline $\begin{array}{l}\mathrm{SPL}^{1} \\
B L P^{1}\end{array}$ & - & 4,50 & 9,00 \\
\hline $\begin{array}{l}\text { Uréia } \\
\text { Urea }\end{array}$ & 0,30 & - & - \\
\hline $\begin{array}{l}\text { Sulfato de amônio } \\
\text { Ammonium sulfate }\end{array}$ & 0,20 & - & - \\
\hline $\begin{array}{l}\text { Cloreto de potássio } \\
\text { Potassium chloride }\end{array}$ & 0,25 & 0,25 & 0,25 \\
\hline $\begin{array}{l}\text { Fosfato bicálcico } \\
\text { Dicalcium phospate }\end{array}$ & 0,20 & 0,30 & 0,40 \\
\hline $\begin{array}{l}\text { Sal mineral* } \\
\text { Mineral salt* }\end{array}$ & 0,73 & 0,53 & 0,43 \\
\hline $\begin{array}{l}\text { Monensina sódica } \\
\text { Monensine }\end{array}$ & 0,025 & 0,025 & 0,025 \\
\hline
\end{tabular}


Tabela 2 - Composição química de ingredientes utilizados no confinamento Table 2 - Chemical composition of ingredients used in the trial

\begin{tabular}{lcccc}
\hline $\begin{array}{l}\text { Fração } \\
\text { Item }\end{array}$ & $\begin{array}{c}\text { Silagem de milho } \\
\text { Corn silage }\end{array}$ & $\begin{array}{c}\text { Milho em grão } \\
\text { Corn grain }\end{array}$ & $\begin{array}{c}\text { Polpa cítrica peletizada } \\
\text { Citrus pulp pellets }\end{array}$ & $\begin{array}{c}\text { Farelo de soja } \\
\text { Soybean meal }\end{array}$ \\
\hline $\begin{array}{l}\text { Matéria seca (\%) } \\
\text { Dry matter (\%) }\end{array}$ & 33,67 & 87,99 & 90,43 & 87,60 \\
$\begin{array}{l}\text { Proteína bruta* } \\
\text { Crude protein* }\end{array}$ & 7,36 & 8,58 & 5,49 & 46,80 \\
$\begin{array}{l}\text { Nitrogênio não-protéico* } \\
\text { Nonproteic nitrogen* }\end{array}$ & 0,29 & - & 0,27 & 0,38 \\
$\begin{array}{l}\text { Fibra detergente neutro* } \\
\text { Neutral detergent fiber* }\end{array}$ & 64,71 & 13,46 & 32,24 & 29,62 \\
$\begin{array}{l}\text { Matéria mineral* } \\
\text { Ash* }\end{array}$ & 5,32 & 1,16 & 6,10 & 6,32 \\
$\begin{array}{l}\text { Cálcio* } \\
\text { Calcium* }\end{array}$ & 0,18 & 0,05 & 1,54 & 0,29 \\
$\begin{array}{l}\text { Fósforo* } \\
\text { Phosphorus* }\end{array}$ & 0,13 & 0,17 & 0,09 & 0,53 \\
\hline
\end{tabular}

* Porcentagem na matéria seca (percentage of dry matter).

concentrado semanalmente, considerando-se o consumo na semana anterior. As sobras foram retiradas duas vezes por semana, sendo amostradas semanalmente, para estimação do teor de matéria seca. Para a mistura do concentrado nos tratamentos com o subproduto, o SPL foi inicialmente misturado ao milho em grão triturado e, em seguida, esses alimentos foram colocados no misturador junto com os demais ingredientes da ração.

O confinamento teve duração de 171 dias, sendo os primeiros 56 dias de adaptação. Os animais foram pesados no início do período de adaptação, no início e no final do período experimental e a cada 28 dias, após jejum completo de 18 horas, para cálculo das variáveis pesos inicial e final, ganho de peso, consumo diário de matéria seca, consumo de matéria seca em relação ao peso e eficiência alimentar.

No final do confinamento, os animais foram abatidos para determinação do peso e rendimento de carcaça, da área de olho de lombo entre a $12^{a}$ e e a $13^{a} \underline{a}$ costelas, da espessura de gordura sobre a $12^{2}$ costela e dos pesos do fígado e do rim. Foi também verificada a ocorrência de abscessos no fígado, com o intuito de avaliar se a porcentagem de concentrado na dieta afetou negativamente o metabolismo dos animais (Elanco, 1974).

Todas as variáveis foram analisadas quanto à normalidade de distribuição e homogeneidade da variância pelo teste de Bartlett (SAS, 1996), a 5\% de probabilidade, e os resultados foram então avaliados estatisticamente por regressão polinomial.

\section{Resultados e Discussão}

A composição química do subproduto concentrado da produção de lisina (SPL) encontra-se na Tabela 3. O teor de matéria seca obtido foi semelhante ao observado por Zakharyan et al. (1986), Hannon \& Trenkle (1990) e Ulbrich et al. (1993) e o SPL apresentou diferenças em sua composição conforme o local produzido. Neste trabalho, não foram encontradas as frações extrato etéreo e fibra bruta, contrariando os resultados obtidos por Zakharyan et al. (1986). A matéria mineral variou consideravelmente dos valores relatados na literatura.

Também houve variação no teor de proteína bruta em comparação aos resultados descritos na literatura. Foram realizadas periodicamente análises da fração protéica do SPL e os resultados indicam a ocorrência de perdas dessa fração por volatilização com o tempo de armazenagem do subproduto. A composição química do SPL obtida por Oliveira et al. (2000) foi muito próxima à deste experimento, mas o teor de nitrogênio total foi inferior (12,1\% na matéria seca).

A forma do nitrogênio do SPL é, na maior parte, não-protéica, em torno de $79 \%$, e, nesse aspecto, os resultados obtidos foram semelhantes aos reportados na literatura (Hannon \& Trenkle, 1990; Bokori et al., 1992; Ulbrich et al., 1993; Oliveira et al., 2000).

O SPL apresentou densidade de $1,205 \mathrm{~kg} / \mathrm{L}$ e o $\mathrm{pH}$ $(6,3)$ foi mais elevado que o observado por Hannon \& Trenkle (1990) e Bokori et al. (1992). Como comen- 
Tabela 3 - Composição químico-bromatológica do subproduto concentrado da produção de lisina (SPL), nas matérias natural e seca

Table 3 - Chemical composition of the byproduct of lysine production (BLP) as-fed and on dry matter basis

\begin{tabular}{lcc}
\hline $\begin{array}{l}\text { Fração } \\
\text { Item }\end{array}$ & $\begin{array}{c}\text { \% da matéria natural } \\
\text { \% as-fed }\end{array}$ & $\begin{array}{c}\text { \% da matéria seca } \\
\text { \% of dry matter }\end{array}$ \\
\hline $\begin{array}{l}\text { Matéria seca } \\
\begin{array}{l}\text { Dry matter } \\
\text { Proteína bruta } \\
\text { Crude protein }\end{array}\end{array}$ & 38,2 & 100 \\
$\begin{array}{l}\text { Nitrogênio total } \\
\text { Total nitrogen }\end{array}$ & 32,5 & 85,1 \\
$\begin{array}{l}\text { Nitrogênio não-protéico } \\
\text { Nonprotein nitrogen } \\
\text { Matéria mineral } \\
\text { Ash }\end{array}$ & 4,1 & 13,6 \\
\hline
\end{tabular}

tado por Bokori et al. (1992), o SPL apresentou leve odor de melaço.

Na Tabela 4 são apresentados os teores de macro e microminerais no SPL.

O teor de enxofre foi inferior ao descrito por Zakharyan et al. (1986), mas, pela alta concentração desse mineral no SPL, deve-se fazer o balanceamento de rações contendo esse subproduto para bovinos, para que os níveis de enxofre na dieta não ultrapassem os limites recomendados (NRC, 1996), e não prejudique o consumo de alimento pelos animais. Não foram registrados níveis de outros minerais suficientes para afetar o consumo de alimentos.

Não foi detectada a presença de selênio, cádmio e arsênio, como relatado por Oliveira et al. (2000). Os níveis de chumbo, níquel e cromo foram inferiores aos níveis considerados tóxicos para bovinos (NRC, 1996), como também foi reportado por Bokori et al. (1992).

A composição mineral foi, de forma geral, muito semelhante aos apresentados por Oliveira et al. (2000).

Na Tabela 5 são apresentados os resultados do aminograma realizado no SPL. Não foram encontrados vários aminoácidos no SPL e os teores daqueles detectados foram baixos, o que era esperado, pois o nitrogênio determinado no SPL estava principalmente na forma não-protéica. O teor de lisina foi inferior ao descrito por Bokori et al. (1992), sugerindo que o processo de extração utilizado no Brasil seja mais eficiente. Entretanto, os níveis de metionina mostraram-se semelhantes.

Durante todo o confinamento, os concentrados foram misturados em quantidade suficiente para uma
Tabela 4 - Composição mineral do subproduto concentrado da produção de lisina (SPL), nas matérias natural e seca

Table 4 - Mineral composition of the byproduct of lysine production (BLP) as-fed and on dry matter basis

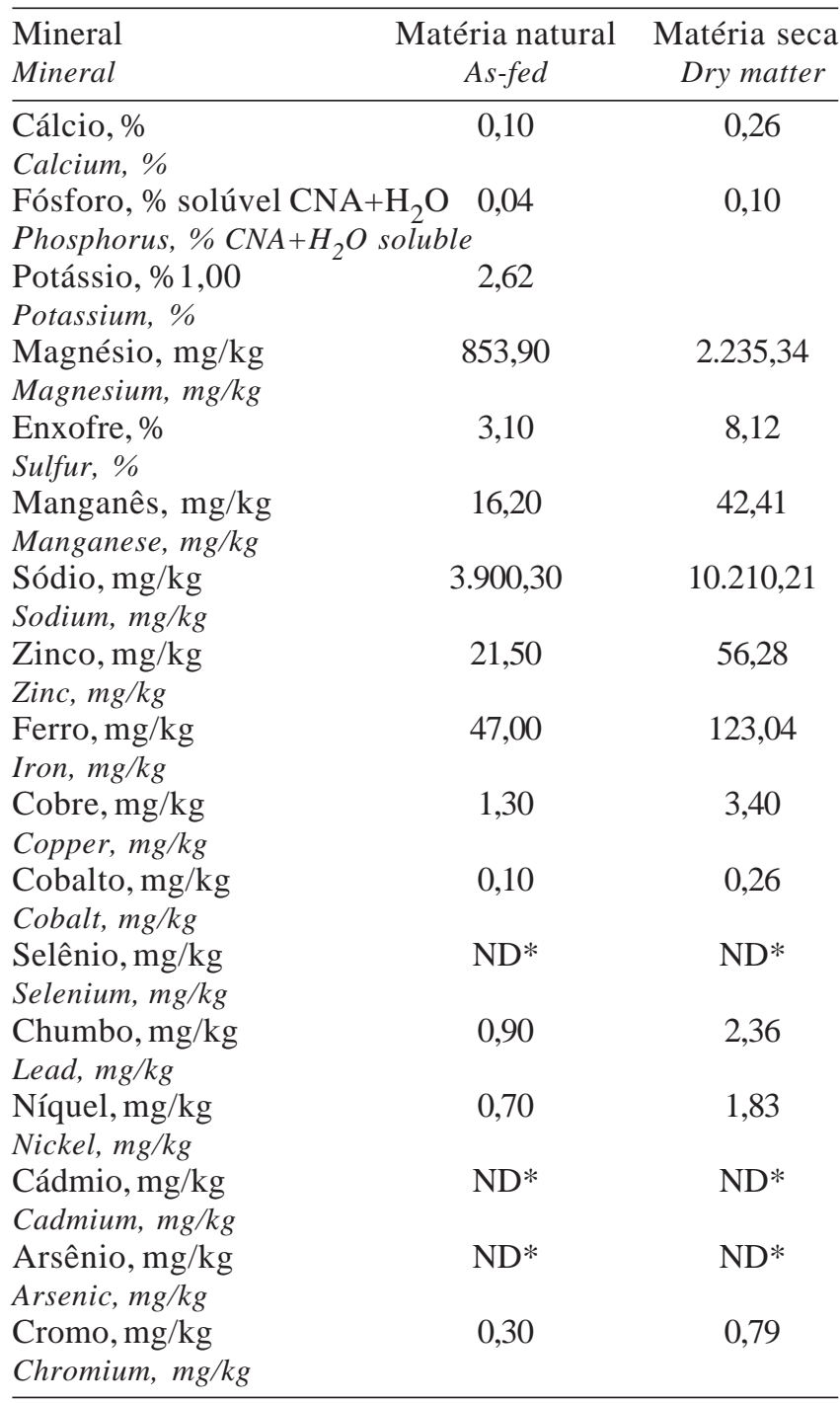

* ND - não-detectado (ND - not detected).

semana, pois o fato de o SPL ser líquido poderia determinar a ocorrência de problemas de degradação em razão da redução da matéria seca, que é a responsável por sua estabilidade aeróbica. Não foram observados problemas aparentes de degradação dos concentrados durante o confinamento.

Nas análises realizadas durante o confinamento, as três dietas experimentais apresentaram teores semelhantes de proteína bruta (em torno de 14\%) e de energia metabolizável (2,79 Mcal/kg de matéria seca).

Os pesos inicial e final, o ganho de peso diário, a ingestão de matéria seca e a eficiência alimentar 
Tabela 5 - Composição em aminoácidos do subproduto concentrado da produção de lisina (SPL), nas matérias natural e seca

Table 5 - Amino acid composition of the byproduct of lysine production (BLP) as-fed and on dry matter basis

\begin{tabular}{|c|c|c|}
\hline Aminoácido & \% na matéria n & na matéria seca \\
\hline Aminoacid & $\%$ as-fed & $\%$ of dry matter \\
\hline Alanina & 0,32 & 0,84 \\
\hline Alanine & & \\
\hline Arginina & $\mathrm{ND}^{*}$ & $\mathrm{ND}^{*}$ \\
\hline Arginine & & \\
\hline Ácido aspártico & 0,02 & 0,05 \\
\hline Aspartic acid & & \\
\hline Glicina & 0,04 & 0,10 \\
\hline Glicyne & & \\
\hline Isoleucina & ND* & ND* \\
\hline Isoleucine & & \\
\hline Leucina & ND* & $\mathrm{ND}^{*}$ \\
\hline Leucine & & \\
\hline Ácido glutâmico & 0,13 & 0,34 \\
\hline Glutamic acid & & \\
\hline Lisina & 0,07 & 0,18 \\
\hline Lysine & & \\
\hline Cistina & $\mathrm{ND}^{*}$ & $\mathrm{ND}^{*}$ \\
\hline Cystine & & \\
\hline Metionina & 0,05 & 0,13 \\
\hline Methionine & & \\
\hline Fenilalanina & $\mathrm{ND}^{*}$ & $\mathrm{ND}^{*}$ \\
\hline Phenylalanine & & \\
\hline Tirosina & $\mathrm{ND}^{*}$ & $\mathrm{ND}^{*}$ \\
\hline Tirosyne & & \\
\hline Treonina & 0,03 & 0,08 \\
\hline Threonine & & \\
\hline Triptofano & ND* & ND* \\
\hline Tryptophan & & \\
\hline Prolina & 0,02 & 0,05 \\
\hline Proline & & \\
\hline Valina & $\mathrm{ND}^{*}$ & ND* \\
\hline Valine & & \\
\hline Histidina & ND* & ND* \\
\hline Histidine & & \\
\hline Serina & ND* & ND* \\
\hline Serine & & \\
\hline
\end{tabular}

* ND - não-detectado (ND - not detected).

encontram-se na Tabela 6. O peso inicial refere-se ao peso dos animais ao início do período experimental e não àquele ao início do período de adaptação. Para as variáveis que apresentaram diferenças significativas entre tratamentos, a equação é apresentada em função da porcentagem de SPL na matéria seca da dieta (X).

Houve efeito quadrático do SPL na dieta sobre o ganho de peso ( $\mathrm{P}=0,0115)$, a ingestão de matéria seca, tanto diária $(\mathrm{P}=0,0693)$ quanto em relação ao peso do animal $(\mathrm{P}=0,0565)$, e o peso final dos animais $(\mathrm{P}=0,0383)$. No entanto, a eficiência alimentar sofreu efeito linear negativo $(\mathrm{P}=0,0212)$ com o aumento do SPL na dieta.

Considerando-se apenas o ganho de peso, 3,72\% de SPL na matéria seca da dieta seria a dose máxima para determinar maior ganho de peso diário. O uso de SPL acima desse nível poderia ocasionar redução no os ganhos de peso dos animais. Os resultados obtidos por Ulbrich et al. (1993) indicaram declínio gradativo do ganho de peso com a inclusão de até 5\% do resíduo da hidrólise do farelo de soja para produção de lisina.

Pelas equações determinadas, calculou-se que as maiores ingestões de matéria seca foram alcançadas com os níveis de 4,67\% de SPL, para a ingestão diária, e de 5,20\%, para a ingestão em relação ao peso vivo. Ou seja, não é possível associar os menores ganhos de peso dos animais nos tratamentos com o SPL ao baixo consumo de alimentos, como sugeriram Endres \& Trenkle (1990).

Os resultados também não podem ser justificados pela proposição de Hannon \& Trenkle (1990) de que o teor de enxofre em doses crescentes de CMS seria o responsável pela redução do ganho de peso, causada pela queda na quantidade de alimento ingerida. Os teores de enxofre das dietas com 4,5 e $9,0 \%$ de SPL foram, respectivamente, de 0,50 e $0,84 \%$ e estão acima dos níveis recomendados pelo NRC (1996), de 0,40\%, e por Hannon \& Trenkle (1990), de 0,30\%, mas, como discutido anteriormente, o consumo máximo de matéria seca calculado foi acima de 4,5\% de SPL. Outros fatores, como alterações metabólicas e eficiência de utilização dos nutrientes, podem ter interferido na redução do ganho de peso antes que fosse atingida a máxima ingestão de alimentos.

É possível calcular, pelas dados apresentados nas tabelas, que os animais do tratamento com 4,5\% de SPL consumiram diariamente $0,933 \mathrm{~kg}$ de SPL e do tratamento com 9,0\%, 1,715 kg. Considerando-se que a densidade do SPL é de $1,205 \mathrm{~kg} / \mathrm{L}$, a quantidade ingerida diariamente foi de 0,744 e $1,423 \mathrm{~L}$, respectivamente para os tratamentos com 4,5 e 9,0\% de SPL.

Uma vez que o máximo ganho de peso foi obtido com 3,72\% de SPL na dieta, estimou-se que os ganhos de peso foram crescentes até a ingestão de $0,771 \mathrm{~kg}$ de SPL por dia (ou 0,640 L por dia). Os resultados foram similares aos reportados por Fekete et al. (1992), que obtiveram aumento no ganho de peso de novilhas consumindo até $600 \mathrm{~mL}$ de CMS por dia e recomendaram dose de 1 a 1,5 g de CMS por kg de peso vivo do animal. Neste estudo, a dose de SPL 
Tabela 6 - Desempenho dos animais de acordo com os tratamentos Table 6 - Performance of animals in each treatment

\begin{tabular}{|c|c|c|c|c|}
\hline \multirow[t]{2}{*}{$\begin{array}{l}\text { Parâmetro } \\
\text { Parameter }\end{array}$} & \multicolumn{3}{|c|}{$\begin{array}{l}\text { Tratamento - Porcentagem SPL } \\
\text { Treatment - Percentage BLP }\end{array}$} & \multirow[t]{2}{*}{$\begin{array}{l}\mathrm{CV}^{1} \\
(\%)\end{array}$} \\
\hline & 0 & 4,5 & 9,0 & \\
\hline $\begin{array}{l}\text { Peso inícial, kg } \\
\text { Initial weight, kg }\end{array}$ & 317,1 & 313,7 & 313,1 & 5,53 \\
\hline $\begin{array}{l}\text { Peso final }{ }^{3}, \mathrm{~kg} \\
\text { Final weight }^{3}, \mathrm{~kg}\end{array}$ & 437,4 & 450,5 & 416,2 & 5,92 \\
\hline $\begin{array}{l}\text { Ingestão de } \mathrm{MS}^{2}, 4, \mathrm{~kg} / \mathrm{dia} \\
\mathrm{DM}^{2} \text { intake }^{4}, \mathrm{~kg} / \text { day }\end{array}$ & 7,17 & 7,92 & 7,28 & 11,68 \\
\hline $\begin{array}{l}\text { Ingestão de MS }{ }^{2}, 5 \text {, \% peso } \\
D M^{2} \text { intake }^{5}, \% \text { body weight }\end{array}$ & 1,90 & 2,07 & 1,98 & 7,94 \\
\hline $\begin{array}{l}\text { Ganho de peso }{ }^{6}, \mathrm{~kg} / \mathrm{dia} \\
\text { Body weight } \text { gain }^{6}, \mathrm{~kg} / \text { day }\end{array}$ & 1,082 & 1,227 & 0,929 & 17,60 \\
\hline $\begin{array}{l}\text { Eficiência alimentar }{ }^{7}, \mathrm{~kg} \text { ganho/kg MS } 2 \text { ingerida } \\
\text { Efficiency }^{7}, \mathrm{~kg} \text { gain } / \mathrm{kg} \mathrm{DM}^{2} \text { intake }\end{array}$ & 0,152 & 0,154 & 0,128 & 13,76 \\
\hline $\begin{array}{l}{ }_{1}^{1} \mathrm{CV} \text { - Coeficientes de variação (Coefficients of variation). } \\
{ }^{2} \mathrm{MS}-\text { Matéria seca }(D M-\text { Dry matter). } \\
3 \hat{Y}=437,4444+8,1852 X-1,1715 X^{2}\left(R^{2}=0,62\right) \\
4 \hat{Y}=7,1733+0,3194 X-0,0342 X^{2}\left(R^{2}=0,98\right) \\
5 \hat{Y}=1,90+0,0679 X-0,0065 X^{2}\left(R^{2}=0,78\right) \\
6 \hat{Y}=1,0823+0,0814 X-0,0109 X^{2}\left(R^{2}=0,74\right) \\
{ }^{7} \hat{Y}=0,1568-0,0027 X\left(R^{2}=0,29\right) .\end{array}$ & & & & \\
\hline
\end{tabular}

obtida no ponto máximo de ganho de peso foi de $2,02 \mathrm{~g}$ por $\mathrm{kg}$ de peso do animal.

Oliveira et al. (2000) obtiveram melhoria no desempenho de bovinos em terminação recebendo $300 \mathrm{~mL}$ de SPL. Entretanto, com 600 mL, constataram redução do ganho de peso dos animais, apesar de o consumo não ter sido alterado, como ocorrido neste estudo. Ou seja, com níveis mais altos de SPL, a ingestão de alimentos diminuiu mais que o ganho de peso, que foi reduzido com porcentagens inferiores desse subproduto. Os autores observaram, no entanto, redução no ganho de peso dos animais com níveis mais baixos de SPL que neste experimento, porém, a dieta utilizada era composta por $65 \%$ de volumoso e silagem de baixa qualidade. Portanto, a qualidade da dieta parece ser fator importante na determinação do nível máximo de SPL a ser utilizado.

Os resultados referentes às características das carcaças, incluindo peso e rendimento de carcaça, espessura de gordura, área de olho de lombo, peso da gordura renal-pélvica-inguinal e do fígado são apresentados na Tabela 7.

Houve efeito quadrático ( $\mathrm{P}=0,0741)$ dos níveis de SPL na matéria seca sobre o peso da carcaça e redução linear $(\mathrm{P}=0,0565)$ sobre o rendimento de carcaça. $\mathrm{O}$ peso do fígado e a espessura de gordura sobre a 12 a costela aumentaram $(\mathrm{P}=0,0875$ e 0,0466 , respectivamente) com maiores participações do SPL na dieta. A área de olho de lombo, mesmo por $100 \mathrm{~kg}$ de carcaça, não foi alterada pelo nível de SPL. Esses resultados diferem dos obtidos por Endres \& Trenkle (1990), que observaram redução da espessura de gordura apenas com níveis a partir de 10\% de CMS na dieta e não notaram alterações no rendimento de carcaça e na área de olho de lombo, mesmo com os níveis mais altos de participação do CMS na dieta.

O maior peso de carcaça, obtido no tratamento com 4,5\% de SPL, resultou do maior ganho de peso e, portanto, do maior peso final dos animais, mas o menor rendimento de carcaça comprovou que o SPL pode provocar aumento do peso das partes não-integrantes da carcaça, como ocorreu com o peso de fígado.

De qualquer modo, não foram verificados abscessos no fígado em nenhum dos animais, independentemente do tratamento a que foram submetidos, demonstrando que dietas com altos teores de concentrado podem ser utilizadas na terminação de bovinos em confinamento, desde que sejam feitas adaptações dos animais ao alimento e que o manejo seja adequado. Ressalta-se que, na dieta utilizada neste experimento, além dos $80 \%$ de concentrado, $40 \%$ da matéria seca da silagem foi composta por grão de milho, perfazendo um total de $88 \%$ de concentrado. 
Tabela 7 - Características da carcaça dos animais em cada tratamento Table 7 - Carcass traits of animals for each treatment

\begin{tabular}{|c|c|c|c|c|}
\hline \multirow[t]{2}{*}{$\begin{array}{l}\text { Parâmetro } \\
\text { Parameter }\end{array}$} & \multicolumn{3}{|c|}{$\begin{array}{l}\text { Tratamento - Porcentagem SPL } \\
\text { Treatment-Percentage BLP }\end{array}$} & \multirow[t]{2}{*}{$\begin{array}{l}\mathrm{CV}^{1} \\
(\%)\end{array}$} \\
\hline & 0 & 4,5 & 9,0 & \\
\hline $\begin{array}{l}\text { Peso da carcaça quente' }, \mathrm{kg} \\
\text { Hot carcass weight }{ }^{2}, \mathrm{~kg}\end{array}$ & 243,65 & 247,33 & 226,85 & 6,47 \\
\hline $\begin{array}{l}\text { Rendimento de carcaça }{ }^{3}, \% \\
\text { Carcass dressing } \% \text {, }\end{array}$ & 55,68 & 54,88 & 54,07 & 2,24 \\
\hline $\begin{array}{l}\text { Espessura de gordura }{ }^{4}, \mathrm{~mm} \\
\text { Backfat thickness }{ }^{4}, \mathrm{~mm}\end{array}$ & 4,72 & 5,61 & 5,83 & 20,28 \\
\hline $\begin{array}{l}\text { Área de olho de lombo, } \mathrm{cm}^{2} \\
\text { Longissimus muscle área, } \mathrm{cm}^{2}\end{array}$ & 57,99 & 56,42 & 53,55 & 10,42 \\
\hline $\begin{array}{l}\text { Área de olho de lombo, } \mathrm{cm}^{2} / 100 \mathrm{~kg} \text { carcaça } \\
\text { Longissimus muscle area, } \mathrm{cm}^{2} / 100 \mathrm{~kg} \text { carcass }\end{array}$ & 23,87 & 22,93 & 23,70 & 9,82 \\
\hline $\begin{array}{l}\text { Peso do fígado }{ }^{5}, \mathrm{~kg} \\
\text { Liver weight }{ }^{5}, \mathrm{~kg}\end{array}$ & 4,51 & 5,14 & 5,11 & 14,18 \\
\hline $\begin{array}{l}\text { Peso dos rins, } \mathrm{kg} \\
\text { Kidney weight, } \mathrm{kg}\end{array}$ & 0,81 & 0,89 & 0,91 & 18,53 \\
\hline
\end{tabular}

\section{Conclusões}

O subproduto concentrado da produção de lisina pode ser utilizado como alimento para tourinhos em confinamento em níveis de até 3,7\% da matéria seca da dieta, substituindo todo o nitrogênio não-protéico e parte do nitrogênio protéico, desde que o balanceamento da dieta seja adequado e que sejam utilizadas dietas com alto teor de energia e com volumoso de alta qualidade.

Estudos metabólicos mais específicos são necessários para determinação dos efeitos de doses elevadas de SPL sobre o ganho de peso dos animais.

\section{Literatura Citada}

ASSOCIATION OF OFFICIAL ANALYTICAL CHEMISTS AOAC. Official methods of analysis. 16.ed. Washington, D.C.: 1995. v.1, p.1-30.

BOKORI, J.; FEKETE, S.; ANDOR, A. et al. Feeding value and possibility of use of the by-product of lysine production ("Protoferm" or CMS) in animal nutrition. I. Physical and chemical characteristics of "Protoferm", physiological observations when fed to dairy cows and fattening steers. Magyar Allatorvosok Lapja, v.47, n.8, p.395-402, 1992. (CAB Abstracts) CD-ROM

CALIXTO, M.G. Efeito da monensina sobre a degradabilidade de ingredientes e rações contendo bagaço hidrolisado e subproduto da produção de lisina. Jaboticabal: Universidade
Estadual Paulista, 2001. 75p. Monografia (Trabalho de Graduação) - Universidade Estadual Paulista, 2001.

ELANCO. Tylan premix for beef cattle. Indianapolis, 1974. p.4-5. (Technical Bulletin)

ENDRES, M.I.; TRENKLE, A. Evaluation of modified condensed molasses solubles (CMS) as a supplement for cattle. Beef-sheep Research Report. Iowa: Iowa State University, 1990. p.114-116.

ENDRES, M.I.; TRENKLE, A. Effects of feeding fractions of condensed molasses solubles on feed consumption by cattle. Beef-sheep Research Report. Iowa: Iowa State University, 1991. p.143-146.

FEKETE, S.; BOKORI, J.; ANDRASOFSZKY, E. et al. Feeding value and possibility of use of the by-product of lysine production ("Protoferm" or CMS) in animal nutrition. II. Determination of the feeding value of "Protoferm" in growing heifers, fattening lambs and rats. Magyar Allatorvosok Lapja, v.47, n.12, p.658668, 1992. (CAB Abstracts) CD-ROM

HANNON, K.; TRENKLE, A. Evaluation of condensed molasses fermentation solubles as a nonprotein nitrogen source for ruminants. Journal of Animal Science, v.68, n.9, p.2634-2641, 1990.

NATIONAL RESEARCH COUNCIL - NRC. Nutrient requeriments of beef cattle. 7.ed. Washington, D.C.: 1996. 212p.

OLIVEIRA, D.J.C.; BERGAMASCHINE, A.F.; ALVES, J.B. Avaliação do subproduto da produção de lisina para bovinos - digestibilidade das dietas e desempenho em confinamento. Ciência Agrotécnica, v.24, n.3, p.756-765, 2000.

SNIFFEN, C.J.; O'CONNOR, J.D.; Van SOEST, P.J. et al. A net carbohydrate and protein system for evaluating cattle diets. II. Carbohydrate and protein availability. Journal of Animal Science, v.70, n.11, p.3562-3577, 1992. 
STATISTICAL ANALYSIS SYSTEM - SAS. User's guide: statistic. 6.ed. Cary, 1996. 956p.

ULBRICH, M.; AL-BAKKOUR, Y.; GEIBLER, C. et al. Die verwendung eines hidrolyserückstandes aus der lysinherstellung im strohkonzentratgemisch für mastlämmer. Arch. Anim. Nutr., v.44, n.2, p.175-185, 1993.

Van SOEST, P.J.; ROBERTSON, J.B.; LEWIS, B.A. Methods of dietary fiber, neutral detergent fiber, and nonstarch polysaccharides in relation to animal nutrition. Journal of Dairy Science, v.74, n.10, p.3583-3597, 1991.
ZAKHARYAN, G.P.; MELIKBEKYN, N.O.; KIRAKOSYAN, L.G. Effect of amonbakterin on milk yield of cows. Izvestiya Sel'Skokhozyaistvennykh Nauk Armenskoi Ssr, n.7, p.70-73, 1986. (CAB Abstracts) CD-ROM

Recebido em: 20/10/04

Aceito em: 06/07/05 